\title{
Seasonal logging, process response, and geomorphic work
}

\author{
C. H. Mohr ${ }^{1}$, A. Zimmermann ${ }^{1}$, O. Korup ${ }^{1}$, A. Iroumé ${ }^{2}$, T. Francke ${ }^{1}$, and A. Bronstert ${ }^{1}$ \\ ${ }^{1}$ Institute of Earth and Environmental Science, University of Potsdam, Potsdam, Germany \\ ${ }^{2}$ Faculty of Forest Sciences and Natural Resources, Universidad Austral de Chile, Valdivia, Chile
}

Correspondence to: C. H. Mohr (cmohr@uni-potsdam.de)

Received: 9 July 2013 - Published in Earth Surf. Dynam. Discuss.: 5 September 2013

Revised: 30 January 2014 - Accepted: 5 February 2014 - Published: 4 March 2014

\begin{abstract}
Deforestation is a prominent anthropogenic cause of erosive overland flow and slope instability, boosting rates of soil erosion and concomitant sediment flux. Conventional methods of gauging or estimating post-logging sediment flux often focus on annual timescales but overlook potentially important process response on shorter intervals immediately following timber harvest. We resolve such dynamics with nonparametric quantile regression forests $(\mathrm{QRF})$ based on high-frequency $(3 \mathrm{~min})$ discharge measurements and sediment concentration data sampled every $30-60 \mathrm{~min}$ in similar-sized $\left(\sim 0.1 \mathrm{~km}^{2}\right)$ forested Chilean catchments that were logged during either the rainy or the dry season. The method of QRF builds on the random forest algorithm, and combines quantile regression with repeated random sub-sampling of both cases and predictors. The algorithm belongs to the family of decision-tree classifiers, which allow quantifying relevant predictors in high-dimensional parameter space. We find that, where no logging occurred, $\sim 80 \%$ of the total sediment load was transported during extremely variable runoff events during only $5 \%$ of the monitoring period. In particular, dry-season logging dampened the relative role of these rare, extreme sediment-transport events by increasing load efficiency during more efficient moderate events. We show that QRFs outperform traditional sediment rating curves (SRCs) in terms of accurately simulating short-term dynamics of sediment flux, and conclude that QRF may reliably support forest management recommendations by providing robust simulations of post-logging response of water and sediment fluxes at high temporal resolution.
\end{abstract}

1

\section{Introduction}

Increased soil erosion ranks among the least disputed geomorphic consequences of timber harvesting (Gomi et al., 2005; Sidle et al., 2006). The major impacts occur during and a few years after harvesting operations, before the vegetation re-establishes and the road surfaces and embankments stabilize. Clear cutting may intensify erosive overland flow (Malmer and Grip, 1990) and cause debris flows and riverbank erosion (Gomi et al., 2004), eventually releasing infrequent sediment pulses into the drainage network. Landsliding may further intensify due to modified drainage areas following the construction of timber roads (Montgomery et al., 2000). As a result, boosted erosion and re-deposition of soil promote the long-term degradation of soil and water re- sources not only on harvest patches but also often in downstream areas (Sidle et al., 2006).

Clear cutting is the most common technique for harvesting timber in the plantation forests of Chile. The nation is currently intensifying and extending its forestry sector, and recent projections point to increasing growth rates of timber and cellulose production (FAO, 2010), as well as an exacerbation of soil erosion in the future. At the same time, the forestry sector provides a major income source and thus a comprehensive assessment of the economic, social, and ecological benefits of forestry is required. Reliable knowledge of pre- and post-disturbance sediment fluxes is vital in this regard, and may be acquired by physics-based modelling or statistical treatment of field data. This holds particularly true for Chile, where law mandates immediate reforestation after 
a

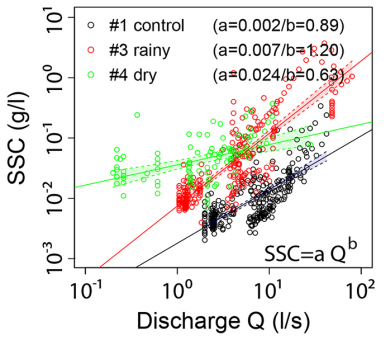

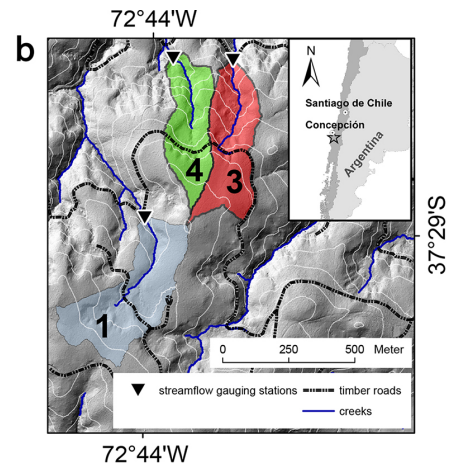

Figure 1. (a) Sediment rating curves for the catchments with fitted power-law intercepts $a\left(\mathrm{gs}^{b} \mathrm{~L}^{-(b+1)}\right)$, slopes $b$, and $95 \%$ confidence intervals about regression lines. (b) Location of study catchments (star in inset) including stream gauges, nearest rain gauge, and unpaved timber roads. Topography derived from lidar survey; contour spacing is $20 \mathrm{~m}$. Numbers (consistent with previous work) refer to catchments. See Huber et al. (2010), Mohr et al. (2012), and Mohr et al. (2013) for detailed descriptions of these catchments.

clear cuttings. However, in many situations, sample size for a robust assessment remains limited, because both time and resources for sampling hydro-geomorphic impacts are often tightly constrained; hence the acquired field data may not represent the full range of water and sediment fluxes. This limited data availability requires an analysis technique capable of dealing with few samples of high variance under changing environmental conditions (Fig. 1a).

Conventional sediment rating curves (SRC) rely on an empirical relationship between water discharge and suspended sediment concentration (SSC), but are prone to high uncertainty where SSC-discharge dynamics are subject to disturbances or nonlinear effects. Recent work revealed that antecedent rainfall, intra-event discharge dynamics (Francke et al., 2008a; Zimmermann et al., 2012), and disturbances due to clear cutting (Mohr et al., 2013) strongly bias SSC prediction based on SRC. This calls for methods capable of reliably simulating antecedent and changing environmental conditions, and predicting SSC following clear cuts. Ideally, such methods should not only sufficiently capture the high rates of sediment transport immediately following timber harvest (e.g. Walsh et al., 2011) but also the underlying process dynamics. Except for very few studies, e.g. Webb et al. (2012), most work set out to quantify erosion response to logging has largely neglected high-frequency time series of water and sediment flux. Here we use quantile regression forests (QRF), a robust multivariate and non-parametric regression technique (Meinshausen, 2006), as a viable and more robust alternative to the traditional SRC approach. We are motivated by the successful application of QRF to model multiple SSC peak events and hysteresis loops between stream flow and suspended sediment discharge (Francke et al., 2008a, b; Zimmermann et al., 2012).

In this study we apply QRF to predict from a highfrequency $(3 \mathrm{~min}$ ) time series of stream discharge and discrete SSC samples the impacts of different seasonal logging on the frequency-magnitude distribution of catchment sediment flux. We show that this technique allows for resolving changes in the distribution of geomorphic work at hitherto unprecedented detail, thus providing unique insights into hydro-geomorphic process dynamics following forestry operations.

\section{Study sites}

We focus on three small $\left(\sim 0.1 \mathrm{~km}^{2}\right)$ headwater catchments that are part of a network of 11 experimental catchments in the coastal mountains of south-central Chile, close to the city of Nacimiento in the Biobio River basin (Fig. 1b). The catchments have largely similar size, geology, soils, hydrogeology, and vegetation, but differing forestry practices. All catchments are comparable in terms of topography; for example, catchment slopes range between $14.2^{\circ} \pm 8.6^{\circ}$ and $20.4^{\circ} \pm 10.8^{\circ}$. A more detailed description and discussion of the catchments' morphometric features is stated in Huber et al. (2010) and Mohr et al. (2012). The dominant soil type is a clayey to loamy Luvisol that is locally disturbed by forestry operations and underlain by a deeply weathered saprolite on top of schist bedrock (Mohr et al., 2012). The climate is Mediterranean, and rainfall intensities are low and only rarely exceed $10 \mathrm{~mm} \mathrm{~h}^{-1}$ during single events. Intense convective storms are extremely rare. Previous work shows that only $5 \%$ of the registered rainfall events exceed $23 \mathrm{~mm} \mathrm{~h}^{-1}$ (Mohr et al., 2013).

Two catchments previously planted with Pinus radiata were logged by the same clear-cutting technique during different seasons: catchment 3 was clear-cut during the winter rainy season (July-August 2009), and remained bare for $\sim 1$ year, whereas catchment 4 was harvested during the end of the dry summer season (March-April 2010), and replanted in early spring 2010 (September-October 2010) (Fig. 2a). Both catchments were reforested by Eucalyptus globulus (Schuller et al., 2013). Although clear cutting is permitted under the Chilean standards, the forest companies are requested to adopt best management practices in accordance with Forest Stewardship Council certification agreements. Among other practices, these include cable harvesting on slopes $>30 \%$, the use of ground skidders in areas of lower slopes, the maintenance of riparian buffer strips (which in the study sites are $\sim 7.5 \mathrm{~m}$ wide both sides of the channel network), and piling up forestry residues along contour lines at the end of the harvesting operations. The logging of catchment 4 severely damaged the riparian buffer strip, whereas the buffer strip in catchment 3 remained unaffected by the timber harvest. Overall, $\sim 88 \%$ of the area of catchment 3 were logged, and more in catchment 4 . The clear cut was done using heavy rubber-tired skidders to drag logs uphill to landings, whereas 


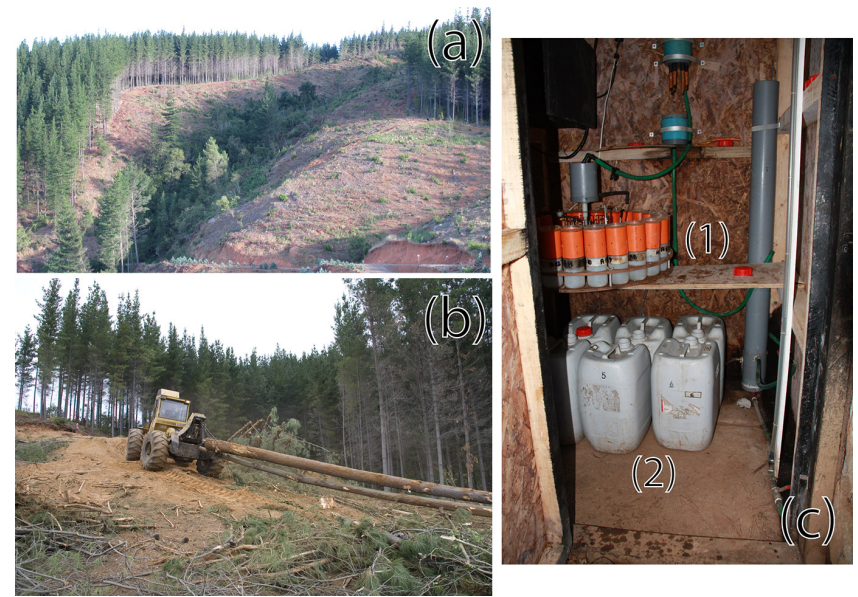

Figure 2. Pictures showing the experimental catchments, the logging procedure, and the suspended sediment monitoring devices. (a) Rainy season logged watershed (watershed 3) in the subsequent dry season (March 2010). (b) Skidder dragging logged stems uphill to the next landing in watershed 3. (c) Custom-built sediment sampling system: (1) horizontal rotating table used to sample suspended sediment per event and (2) recipient used to collect bulk sample of suspended sediment on weekly basis.

cable logging was limited to steep slopes (Mohr et al., 2013) (Fig. 2b). The loggings covered the entire catchment area including their ridges. Catchment 1 remained unlogged and covered with $P$. radiata, and served as a control catchment. On 27 February 2010, the study area was hit by the $\mathrm{M}_{\mathrm{w}} 8.8$ Maule earthquake that caused ground shaking for $2.5 \mathrm{~min}$ at ground accelerations of $\sim 0.3 \mathrm{~g}$. The regional hydrological response featured an abrupt drop in stream discharge followed by a rapid increase (Mohr et al., 2012).

\section{Methods}

\subsection{Field sampling}

We measured stream discharge with V-notch Thompson weirs equipped with custom-built water-stage recorders at a frequency of $3 \mathrm{~min}$, and a water-level accuracy of $2 \mathrm{~mm}$ (Huber et al., 2010; Mohr et al., 2012, 2013). Rainfall was recorded by a Hobo tipping bucket rain gauge with an accuracy of $0.2 \mathrm{~mm}$. A Wilcox rank sum test was used to assess whether hourly rainfall intensities were statistically different $(p \leq 0.05)$ between the years. Total sediment yields estimated by bulk samples from June 2008 to September 2009 in these and adjacent catchments indicate that pine plantations were more prone to soil erosion than eucalyptus plantations ( $\mathrm{Hu}-$ ber et al., 2010). With bed load being negligible in the coastal mountains (Iroumé, 1992), i.e. < $1 \%$ of the total load (Huber and Mohr, unpublished data), we acquired high-frequency data on instantaneous SSC from June 2009 to August 2010 in order to quantify sediment flux in response to logging activi-
Table 1. Number of total samples for each catchment. Sample size of pre-logging period given in parentheses.

\begin{tabular}{llll}
\hline Catchment & Sample number $n$ & Start date & End date \\
\hline 1 & 278 & $06 / 27 / 2009$ & $08 / 15 / 2010$ \\
3 & $276\left(n_{\text {pre }}=89\right)$ & $06 / 27 / 2009$ & $08 / 29 / 2010$ \\
4 & $100\left(n_{\text {pre }}=24\right)$ & $02 / 19 / 2010$ & $08 / 28 / 2010$ \\
\hline
\end{tabular}

ties. We sampled SSC on an event basis with an electric pump attached to a floating device submerging the pump aperture at a constant depth of $5 \mathrm{~cm}$ below the water surface in the weirs. We took instantaneous SSC samples on an event basis at 30 to $60 \mathrm{~min}$ intervals (Fig. 2c). In the absence of significant rainfall events, we took at least one complementary daily sample during February-March and August 2010 for characterizing low-flow conditions (Table 1). All SSC samples were then rounded to the next 3 min interval to synchronize with discharge measurements. SSCs were determined gravimetrically with an accuracy of $0.5 \mathrm{mg}$ after filtering the runoff samples (Mohr et al., 2013). We obtained sediment yields by multiplying the SSC with the runoff volume summed over the respective time intervals

$\operatorname{SSY}=\int_{t 1}^{t 2} Q(t) \operatorname{SSC},(t) \mathrm{d} t$

where SSY is suspended sediment yield $\left(\mathrm{g} \mathrm{s}^{-1}\right), Q(t)$ is instantaneous discharge $\left(\mathrm{L} \mathrm{s}^{-1}\right)$, and $\operatorname{SSC}(t)$ is instantaneous sediment concentration $\left(\mathrm{g} \mathrm{L}^{-1}\right)$.

We complemented this event-based sampling by monitoring suspended sediment flux with weekly volume-weighted bulk sampling (Huber et al., 2010) (Fig. 2c). Despite longer sampling intervals, this alternative monitoring scheme provided data without the need to interpolate SSC. We considered these data as first-order benchmarks for the modelled sediment fluxes. Any given bulk sample merged four samples each day over a period of one week (Huber et al., 2010).

\subsection{Quantile regression forests (QRF)}

Quantile regression forests (QRF) is a robust non-parametric regression technique (Meinshausen, 2006) that builds on Random Forest (RF) regression tree ensembles, a data mining method based on the repeated random selection of both training data and predictors (Breiman, 2001). The method considers the full distribution of tree predictions, thus quantifying inherent uncertainties of each model (Zimmermann et al., 2012). The QRF approach also helps to incorporate effects of variable interaction while at the same time offering means to quantify relative variable importance (Francke et al., 2008a; Zimmermann et al., 2012) by assessing the decline in model performance due to randomizing single 
predictor variables while keeping all other predictors unchanged.

\subsection{QRF model}

We set up individual QRF models for each catchment to predict SSC from the (a) rainfall and discharge time series, (b) day of year to account for possible seasonality effects, and (c) change in discharge to capture dynamics between events (Francke et al., 2008a). We quantified antecedent hydrometeorological conditions by computing predictor variables that integrated antecedent rainfall and discharge values over multiples of the sampling interval. Time interval and number of aggregation levels were set to 3 and 6 , respectively. These settings describe the successive increase of aggregation windows into the past and their total number in the generation of the aggregated predictors. In order to prevent co-linearity, overlaps between each window were avoided (Zimmermann et al., 2012). For example, $P_{28-81}$ refers to the rainfall accumulated between 28 and 81 min prior to a given SSC sample (Zimmermann et al., 2012). In order to account for changing environmental conditions, we added variables accounting for elapsed time after clear cutting to capture possible effects of timber harvest and vegetation recovery over time. We further defined a switch variable that stratified the data into pre- and post-seismic periods to identify potential earthquake impacts (Supplement Table 1).

We assessed the relative predictor importance based on permutation (Strobl et al., 2008). This measure accounts for multi-collinearity and associated overestimation of variable importance due to spurious correlation artefacts (Liaw and Wiener, 2002). We validated model performance applying the root-mean-square error

$\mathrm{RMSE}=\sqrt{\frac{1}{N} \sum_{i=1}^{N}\left(x_{i}-\hat{x}_{i}\right)^{2}}$

for $N$ measurements $x_{i}$ and predictions $\hat{x}_{i}$. In order to avoid arbitrary decisions during the validation procedure, e.g. size and location of the test data set, we applied a 20 -fold cross validation leaving out continuous data blocks of $5 \%$ of the data to test the models, (Zimmermann et al., 2012). We defined $10 \%$ of the SSC range $\left(\mathrm{g} \mathrm{L}^{-1}\right)$ as a threshold range for acceptable model performance accounting for the inherent erosion model limitations (Nearing, 1998) and the distinct parameter range of measured SSC. Finally, we estimated suspended sediment yields for each 3 min time step applying a Monte Carlo simulation (Francke et al., 2008a). To this end we randomly drew a SSC prediction from the distribution realized by the QRF model for each time step. Based on these samples, we estimated event dynamics and both monthly and annual sediment yields by summing up the products of $Q$ and SSC at each time step over each target period. By repeating this procedure 250 times, we obtained a distribution of suspended sediment yields (SSY) estimates which was then inspected to determine whether the data followed a Gaussian distribution. The latter allowed us to calculate their mean value and standard deviation to assess the spread of the predicted sediment yields (Zimmermann et al., 2012).

\subsection{Sediment rating curve (SRC)}

For each catchment, we fitted sediment rating curves to a power-law function relating SSC values to the correlate discharge $Q$ (e.g. Gomi et al., 2005)

$\mathrm{SSC}=a Q^{b}$,

where $a\left(\mathrm{~g} \mathrm{~s}^{b} \mathrm{~L}^{-(b+1)}\right)$ and $b$ are empirical fitting parameters of log-transformed data. Based on the SRC, we predicted SSC during the study period and performed the same 20-fold cross-validation procedure as described for QRF.

\section{Results}

We find that QRF predicted SSC with high accuracy under both low- and high-flow regimes, as well as unlogged and logged conditions. Fig. 3 illustrates the predictive accuracy for high SSC under disturbed conditions, and the additional advantage of QRF to compensate for poor, or impute missing, rainfall and discharge data (Fig. 7a-c). The method also reproduced hysteresis loops and the occurrence of multiple peak events (Fig. 3). Treating errors $<10 \%$ of the measured SSC range as acceptable, both QRF and SRC met this criterion across all catchments (Supplement Table 2). Yet QRF generally outperformed SRC, except for rainy-season logging, where the large range of measured SSC values shrunk relative differences in model performance to $<1 \%$.

We compared monthly and annual specific SSY predicted from both QRF and SRC with the bulk data, using a Monte Carlo simulation (Francke et al., 2008a) (Table 2, Supplement Tables 3-4). Specific sediment yield averaged for the first two years following rainy-season logging was $3.27 \pm 0.09 \mathrm{tha}^{-1}$ or $\sim 20$ times the SSY predicted for unlogged conditions $\left(0.19 \pm 0.004 \mathrm{tha}^{-1}, \pm 1 \sigma\right)$.

However, monthly SSY from the catchment planned to be harvested during rainy season exceeded that in the unlogged control catchment by a factor of $\sim 5$ even before logging commenced (Fig. 4a). Similarly, the catchment that was subjected to dry-season logging yielded $\sim 4$ times the SSY of the control catchment before it was clear-cut (Fig. 4b). The decreasing slope of the double-mass curve after dry-season logging indicates that soil erosion decreased. In contrast, sediment flux intensified over undisturbed conditions after rainyseason logging.

When normalized to the increase under unlogged control conditions, SSYs increased from 2009 to 2010 by 125\% following rainy-season logging, but decreased by $\sim 40 \%$ after dry-season logging. This finding is in line with our bulk data measurements (Table 2). Overall, QRF predicted substantially higher sediment yields than the SRC approach. 
Table 2. Bulk data and modelled annual suspended sediment yields in 2009 and 2010 at the catchment outlets of control (1), rainy-season clear cutting (3), and dry-season clear cutting (4). Annual rainfalls from local rain gauge (Mohr et al., 2012); errors are \pm 1 standard deviation.

\begin{tabular}{lrrrrr}
\hline & Year & $\begin{array}{r}\text { Catchment 1 } \\
\left(\mathrm{tha}^{-1} \mathrm{yr}\right)\end{array}$ & $\begin{array}{r}\text { Catchment 3 } \\
\left(\mathrm{tha}^{-1} \mathrm{yr}\right)\end{array}$ & $\begin{array}{r}\text { Catchment 4 } \\
\left(\mathrm{tha}^{-1} \mathrm{yr}\right)\end{array}$ & $\begin{array}{r}\text { Rainfall } \\
\left(\mathrm{mm} \mathrm{yr}^{-1}\right)\end{array}$ \\
\hline Measured & 2009 & 0.15 & 0.28 & 0.22 & 1463.9 \\
bulk data & 2010 & 0.56 & 0.88 & 0.55 & 1120.8 \\
QRF & 2009 & $0.06 \pm 0.00$ & $0.83 \pm 0.01$ & $0.39 \pm 0.00$ & \\
& 2010 & $0.14 \pm 0.01$ & $2.43 \pm 0.08$ & $0.48 \pm 0.01$ & \\
SRC & 2009 & 0.02 & 0.08 & 0.12 & \\
& 2010 & 0.02 & 0.12 & 0.14 & \\
\hline
\end{tabular}
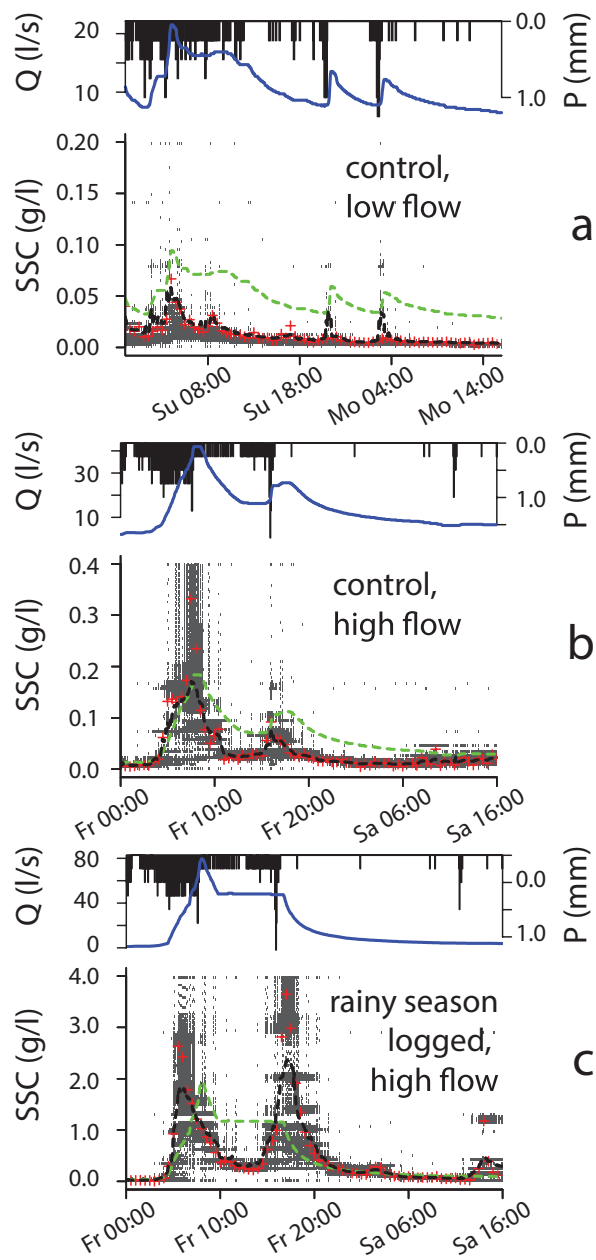

Figure 3. Water discharge and SSC dynamics under unlogged and logged conditions during two rainfall events: (a) 27-29 June 2009, catchment 1; (b-c) 14-15 August 2009, catchments 1 and 3. Density of SSC predictions of the QRF model for each time step encoded by SSC in coloured histograms: black dashed lines are means of these predictions, red crosses are measured SSC, and green dashed lines are SSC predictions of the SRC. Data are from calibration period; that is, periods are covered with SSC samples used for model building (see Fig. 7 for limits to model predictions).
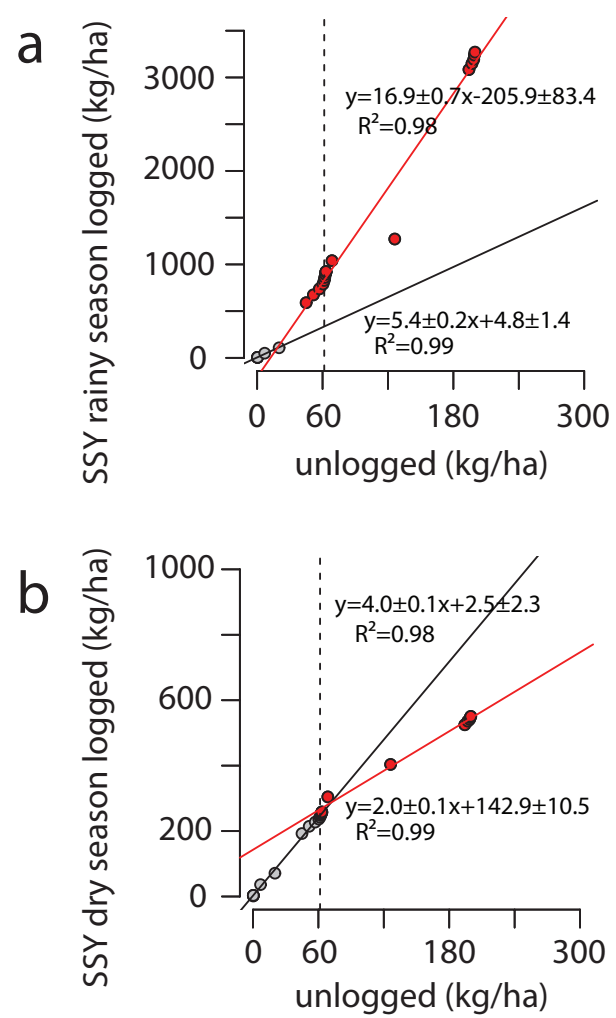

Figure 4. Monthly double-mass-curve analysis between the sediment yields (SSY) of catchments logged during (a) rainy and (b) dry season, and the unlogged control catchment. Black vertical dashed line separates 2009 and 2010 study periods; grey and red circles are pre- and post-logging sediment yields, respectively; lines are best-fit linear regression models. Uncertainties are \pm 1 standard deviation.

Only for undisturbed conditions and dry-season logging were SRC predictions within the same order of magnitude. Based on bulk data, SRC underestimates annual SSY by a factor of 2-28 (Supplement Table 3) despite overestimating sediment flux during individual peak runoff events (Fig. 3, Supplement Fig. 1).

Our QRF-derived estimates show that, under unlogged conditions, $\sim 80 \%$ of the total sediment load carried during the monitoring period was transported during only $\sim 5 \%$ of 

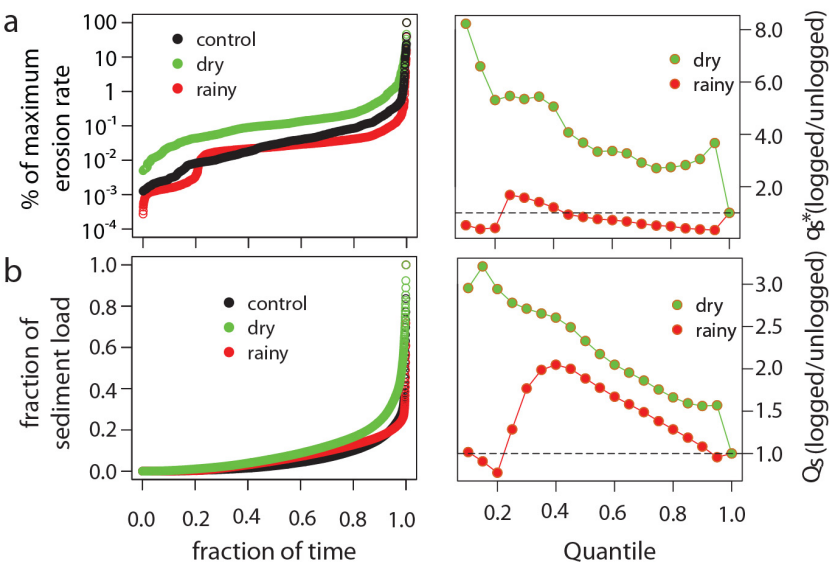

Figure 5. (a) Fraction of instantaneous sediment transport rates normalized to catchment maximum as a function of monitoring time during which these rates were not exceeded. (b) Fraction of total sediment load normalized per catchment as a function of the fraction of total monitoring period for unlogged conditions as well as rainy- and dry-season logging. Right-hand panels show resulting ratios of instantaneous transport rates $q_{\mathrm{s}}^{*}$ and total sediment loads $Q_{\text {s }}$ per quantile for logged versus unlogged conditions. Black horizontal dashed lines are $1: 1$ ratio. Empirical cumulative distribution functions differ significantly ( $p<0.01$, Kolmogorov-Smirnov test).

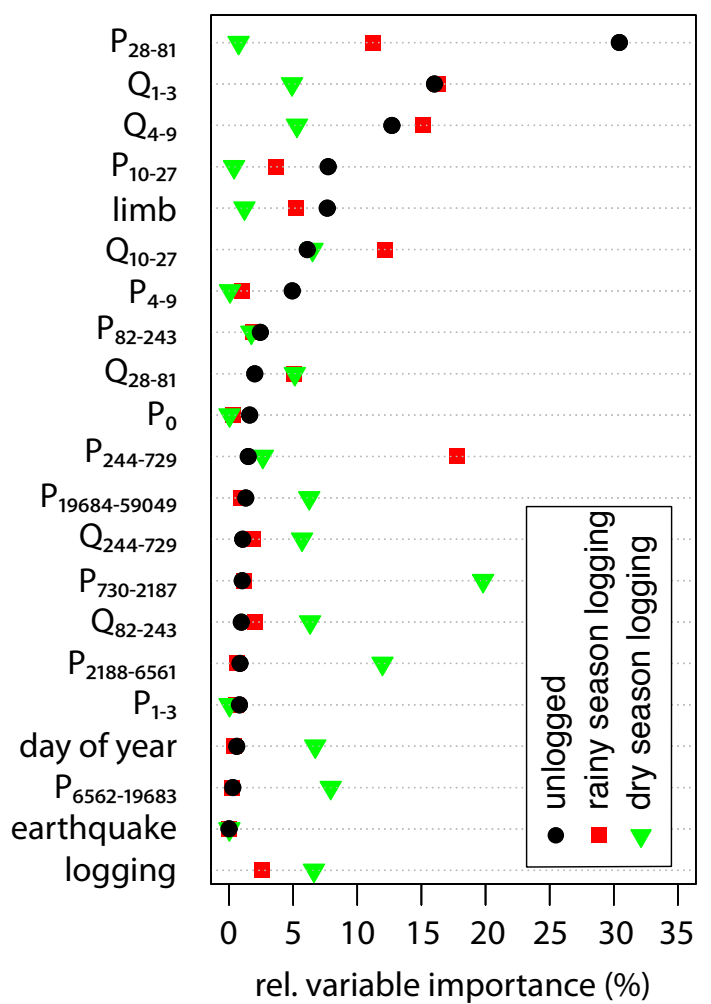

Figure 6. Variable importance of the quantile regression models for each catchment scaled to $100 \%$ in order to facilitate inter-catchment comparison. See Supplement Table 1 for predictor variables.
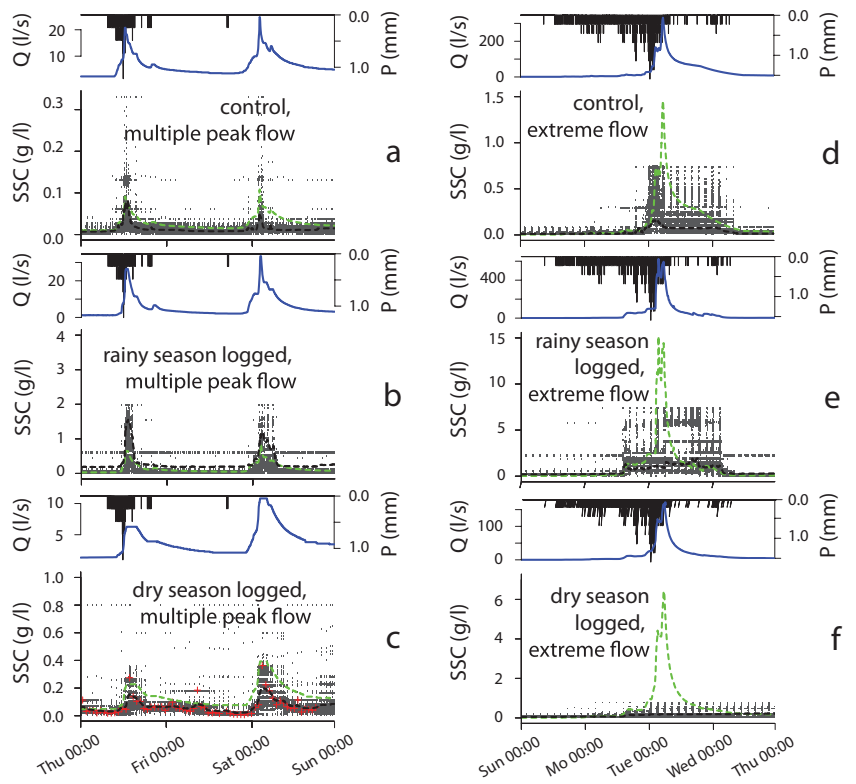

Figure 7. QRF model results of SSC dynamics during extreme peak flow for undisturbed and logged conditions during two rainfall events, i.e. 15-18 August 2010 (a-c) and 26-28 August 2010 (d-f). Density of SSC predictions of the QRF model for each time step encoded by grey histograms, black dashed lines are means of these predictions, and green dashed lines are SSC predictions based on SRCs. In (c), red crosses show measured SSC.

the time. Most of the sediment was transported during rare, large runoff events. The instantaneous flux rate $\left(\mathrm{g} \mathrm{s}^{-1}\right)$ variability of these rare events spanned 4 orders of magnitude, and thus more than the variability of all other rates occurring over $95 \%$ of the monitoring period (Fig. 5a). Our QRF data thus indicate that logging, regardless of its seasonal timing, coincided with a relatively increased contribution of moderate as opposed to extreme runoff events in terms of sediment transport. Thus, immediate post-logging effects on sediment transport involved shifting the geomorphic work towards less flashy and more moderate events. We found this effect to be more pronounced for dry-season than for rainy-season logging (Fig. 5b).

To rank the contributions of different environmental controls as predictors of sediment flux, we quantified their relative importance in terms of added total predictive accuracy (Fig. 6). We found that antecedent rainfall accumulated 28-81 min prior to a given SSC sample was most influential for unlogged conditions, whereas the timing of logging was not. In contrast, logged catchments did not respond to such short-term rainfall memory. Instead, rainfall accumulated over 244-729 min and 730-2181 min showed the highest importance for the catchments clear-cut during the rainy and dry seasons, respectively (Fig. 6). Near-instantaneous discharges cumulated over 1-3 and 4-9 min prior to SSC sampling were important for both unlogged and rainy-season logging catchments. Neither the day of year nor the timing of 
the 2010 earthquake showed any significant influence on the SSC predictions (Fig. 6).

\section{Discussion}

Our results show that high-frequency $(3 \mathrm{~min})$ time series of post-logging water and sediment fluxes are instructive with regard to understanding immediate hydro-geomorphic process response despite several unavoidable uncertainties. For one, we treat our bulk sediment flux measurements as minimum estimates given their low temporal resolution compared to the fast hydrological response. Under such restrictions, we assume that they do not fully capture potentially high but short-lived SSC during intense rainfall events. Thus, the total sediment yields based exclusively on bulk samples are a lower-bound estimate (Table 2). Furthermore, we find that conventional sediment rating curves (SRCs) are sensitive to outliers, resulting in implausibly high SSC (e.g. $10-15 \mathrm{~g} \mathrm{~L}^{-1}$; Fig. 7e), but remain below our QRF predictions on average (Table 2, Supplement Table 5). Under the recorded lowflow regime (Huber et al., 2010), SRCs underestimate the hydro-geomorphic work of more frequent though lower sediment fluxes, while they overestimate the less frequent highermagnitude events. This finding supports earlier work arguing that SRCs significantly underestimate sediment fluxes (e.g. Asselman, 2000).

Overall, the QRF predictions cast a much more detailed and consistent light on high-frequency post-logging sediment flux, particularly with regard to systematic shifts in the frequency-magnitude distribution of high-frequency sediment transport rates and total loads (Fig. 5). The choice of season for clear-cut logging is linked to distinct changes in the relative overall sediment transport efficiency with a general trend towards emphasizing moderate flows, while dampening the efficiency of more rare and extreme events, which we define here as those values above the 95th percentile of our data. Not only do our results significantly expand, down to the process timescale, the notion that extreme sediment transport events may perform the bulk of geomorphic work (Korup, 2012) but our findings also underscore the impact that logging may have on shifting the underlying frequencymagnitude distributions of water and sediment flux (Fig. 5). We interpret these as statistically robust changes, given that QRF avoids over-fitting by randomly selecting both data and predictor subsets, while providing objective measures of their relative importance (Fig. 6). Predictor importance also changes as a function of the logging season. Not only are the resulting predictions in line with the base flow-dominated discharge but they also maintain low uncertainty because of the averaging-out of low-precision predictions (Zimmermann et al., 2012). Nevertheless, QRF may have drawbacks for high-magnitude rainfall-runoff events (Fig. 7d-f) given the method's inability to extrapolate beyond the parameter space. Seasonal effects may not be fully represented in the time series (Fig. 6) because our observation windows in time have significantly different rainfall patterns (Supplement Table 3). Our study area is dominated by frontal rainfall events instead of high-intensity convective storms, and we caution against extrapolating our results for rainfall-runoff events of higher magnitude. In essence, QRF is a robust and versatile method for hindcasting high-frequency time series of water and sediment discharge, but it is not designed for predicting future events.

Compared with similar studies on logging effects (e.g. Gomi et al., 2005), our QRF predictions indicate very low to even slightly decreasing post-logging sediment yields following dry-season logging when compared to unlogged conditions. Our observation of increased post-rainy-season logging sediment flux is consistent with previous work (e.g. Sidle et al., 2006). Yet the magnitude of this increase is small (e.g. Gomi et al., 2004), and our SSY estimates are within the range reported for natural, undisturbed forests (Zimmermann et al., 2012). The observed decreases of SSY following dry logging (Fig. 4b) may partly be due to prompt replanting of the logged slopes (Malmer and Grip, 1990). We exclude topographic controls on sediment flux since slope and stream gradient are highest in catchment 4 (Mohr et al., 2012), where the lowest sediment load had been observed. Sediment flux is expected to be even lower in this catchment assuming the appropriate adoption of best management practices such as maintenance of buffer strips $(\sim 7.5 \mathrm{~m}$ each $)$ alongside the streams. Some maintenance works on a timber road in 2010 in the unlogged catchment are also likely to have contributed to elevating the local sediment supply given that unsealed timber roads may dominate sediment production per unit area in managed forests (e.g. Motha et al., 2003). Consequently, we expect that the thus elevated sediment flux in the unlogged catchment may have partly smothered the relative impact of logging in the other catchments.

We also exclude seasonal meteorological differences as drivers of the elevated SSYs in 2010, as rainfall was much higher in 2009 at comparable intensities (Table 2). Moreover, the timing of the 2010 earthquake did not notably distort any of the SSC predictions (Fig. 6) despite favourable conditions for post-seismic increases in sediment flux (Hovius et al., 2011). The limited earthquake response may be linked to a decisive lack of post-seismic rainfall in 2010, which may have otherwise triggered mass wasting. Plantations of $P$. radiata are prone to mass wasting because of their low root strength compared with other species (Watson et al., 1999). When logged, pine roots rapidly decay in root strength (Sidle, 1991). Shallow landslides are also promoted by slow root-strength recovery rates and cumulative effects of preceding rotations (Sidle et al., 2006). After logging, root decay leads to progressive weakening of slopes over time, whereas regrowth strengthens slopes. The opposing trends lead to maximum mass wasting rate at $\sim 2-3$ years after logging (Watson et al., 1999). Hence, our immediate post-logging predictions of SSC (Fig. 6) are consistent with mechanistic 
slope-stability models (Sidle et al., 2006). During the monitoring period of this study, however, we regard the contribution of mass wasting processes as minor, and hitherto insufficient, for explaining the hydro-geomorphic post-logging regimes.

The ORF-derived variable importance plot supports the notion of a predominant overland flow mechanism of recent harvest areas (Fig. 6). Infiltration capacity may increase on recently logged areas, thus impeding infiltration-excess overland flow generation under the low rainfall intensities observed (Mohr et al., 2013). Alternatively, high-duration rainfall is required to elevate groundwater levels, which in turn initiate erosive saturation-excess overland flow (Dunne and Black, 1970), and connect sediment sources to the drainage network. The relevance of several antecedent rainfall characteristics for predicting post-logging sediment fluxes reflects the local rainfall regime, where low-intensity and longduration rainfall events successively saturate the soil layers over time, thus permitting erosive overland flow (Huber et al., 2010). Compared with rainy-season logging, the measured SSC following dry-season logging also responded to significantly longer time lags. The lower cohesion of wet soil elevates sediment supply for erosive overland flow during timber machinery action in the rainy season. Hence, the susceptibility to soil erosion is higher compared to logging in dry soil conditions. The distinct micro-topography left by heavy machinery persisted following dry-season logging until the subsequent rainy season, thus impeding overland-flow connectivity and requiring larger volumes of water to reestablish connectivity (Mohr et al., 2013). In contrast, SSC under unlogged conditions appears to be modified by more short-term antecedent rainfall characteristics (Fig. 6). Such flashiness may indicate effects of hydrophobic plantation forest cover (e.g. Miyata et al., 2009).

\section{Conclusions}

Our study provides novel insights into the immediate hydrogeomorphic process response to different seasonal timber harvest operations. We find that quantile regression forests (QRF) outperform sediment rating curves (SRC) in terms of accurately predicting post-logging sediment yields at the process scale. Using empirical sediment rating curves may lead to grave underestimates of sediment fluxes from managed forests. Our unprecedented high-frequency data on postlogging water and sediment fluxes from three Chilean headwater basins corroborates the widely held view that most sediment transport is accomplished within a few rare highdischarge events, particularly at the timescale of immediate hydro-geomorphic process response. Moreover, QRF-based hindcasting underlines that it is the seasonal timing of clear cutting that dictates the amount of shift in the frequencymagnitude relationship of sediment transport, eventually redistributing geomorphic work from rare, extreme events to more moderate ones. Dry-season logging led to a much greater dampening of extreme events, whereas rainy-season logging accentuated the contrasts in instantaneous transport rates. Post-logging increases in sediment flux, most likely driven by saturation-excess overland flow, were an order of magnitude higher following rainy-season clear cutting.

With these findings in mind, we conclude that the task of predicting post-logging sediment yields remains a trade-off between model simplicity, applicability, and uncertainty. Our work provides a firm basis for longer-term studies that will complement our results by recording the cumulative net effects of logging and the avenues of hydro-geomorphic recovery. Still, given that data scarcity and variability are common for post-logging disturbances, we find that quantile regression forests are a robust and promising tool for quantifying in detail high-frequency time series of water and sediment fluxes following clear-cut operations.

\section{Supplementary material related to this article is available online at http://www.earth-surf-dynam.net/2/ 117/2014/esurf-2-117-2014-supplement.pdf.}

Acknowledgements. We thank Andreas Bauer, Johannes Brenner, Franziska Faul, Rodrigo Bravo, and Cristian Frêne Conget for helping in the field and during data analysis. We are grateful to Forestal Mininco for providing access to our experimental catchments, and acknowledge Anton Huber for support and advice. We thank Simon Mudd and two reviewers for constructive comments on an earlier draft of this manuscript. This study is co-funded by the International Bureau of the German Federal Ministry of Education and Research and the Chilean government (CONICYT/BMBF 2009-092 and 2010-243).

Edited by: S. Mudd

\section{References}

Asselman, N. E. M.: Fitting and interpretation of sediment rating curves, J. Hydrol, 234, 228-248, 2000.

Breiman, L.: Random forests, Machine Learning, 45, 5-32, 2001.

Dunne, T. and Black, R. D.: An Experimental investigation of runoff production in permeable soils, Water Resour. Res., 6, 478-490, 1970.

FAO: Global Forest Resources Asssessment 2010, Main Report, Food and Agriculture Organization of the United Nations, Rome, 2010.

Francke, T., J.A. Lopez-Tarazon, and Schroder, B.: Estimation of suspended sediment concentration and yield using linear models, random forests and quantile regression forests, Hydrol. Processes, 22, 4892-4904, 2008a.

Francke, T., Lopez-Tarazon, J. A., Vericat, D., Bronstert, A., and Batalla, R. J.: Flood-based analysis of high-magnitude sediment transport using a non-parametric method, Earth Surf. Processes Landforms, 33, 2064-2077, 2008b. 
Gomi, T., Moore, R. D., and Hassan, M. A.: Suspended sediment dynamics in small forest streams of the Pacific Northwest, J. Am. Water Resour. Assoc., 41, 877-898, 2005.

Gomi, T., R. C. Sidle, and Swanston, D. N.: Hydrogeomorphic linkages of sediment transport in headwater streams, Maybeso Experimental Forest, southeast Alaska, Hydrol. Processes, 18, 667683, 2004.

Hovius, N., Meunier, P., Lin, C.-W., Chen, H., Chen, Y.-G., Dadson, S., Horng, M.-J., and Lines, M.: Prolonged seismically induced erosion and the mass balance of a large earthquake, Earth Planet. Sci. Lett., 304, 347-355, 2011.

Huber, A., Iroumé, A., Mohr, C. H., and Frene, C.: Effect of Pinus radiata and Eucalyptus globulus plantations on water resource in the Coastal Range of Biobio region, Chile, Bosque, 31, 219-230, 2010.

Iroumé, A.: Precipitación, escorrentía y producción de sedimentos en suspensión en una cuenca cercana a Valdivia, Chile, Bosque, 13, 15-23, 1992.

Korup, O.: Earth's portfolio of extreme sediment transport events. Earth-Sci. Rev., 112, 115-125, 2012.

Liaw, A., and Wiener, M.: Classification and Regression by randomForest, R News, 2, 18-22, 2002.

Malmer, A. and Grip, H.: Soil disturbance and loss of infiltrability caused by mechanized and manual extraction of tropical rainforest in Sabah, Malaysia, Forest Ecol. Manag., 38, 1-12, 1990.

Meinshausen, N.: Quantile regression forests, J. Machine Learning Res., 7, 983-999, 2006.

Miyata, S., Kosugi, K., Gomi, T., and Mizuyama, T.: Effects of forest floor coverage on overland flow and soil erosion on hillslopes in Japanese cypress plantation forests, Water Resour. Res., 45, doi:10.1029/2008WR007270, 2009.

Mohr, C. H., Montgomery, D. R., Huber, A., Bronstert, A., and Iroumé, A.: Streamflow response in small upland catchments in the Chilean coastal range to the M-W 8.8 Maule earthquake on 27 February 2010, J. Geophys. Res.: Earth Surf., 117, F02032, doi:10.111029/2011JF002138, 2012.

Mohr, C. H., Coppus, R., Huber, A., Iroumé, A., and Bronstert, A.: Runoff Generation and soil erosion processes after clear cutting, J. Geophys. Res.: Earth Surf., 118, 814-831, doi:10.1002/jgrf.20047, 2013.
Montgomery, D. R., Schmidt, K. M., Greenberg, H. M., and Dietrich, W. E.: Forest clearing and regional landsliding, Geology, 28, 311-314, 2000.

Motha, J. A., Wallbrink, P. J., Hairsine, P. B., and Grayson, R. B.: Determining the sources of suspended sediment in a forested catchment in southeastern Australia, Water Resour. Res., 39, doi:10.1029/2001WR000794, 2003.

Nearing, M. A.: Why soil erosion models over-predict small soil losses and under-predict large soil losses, Catena, 32, 15-22, 1998.

Schuller, P., Walling, D. E., Iroumé, A., Quilodran, C., Castillo, A. and Navas, A.: Using ${ }^{137} \mathrm{Cs}$ and ${ }^{210} \mathrm{~Pb}$ and other sediment source fingerprints to document suspended sediment sources in small forested catchments in south-central Chile, J. Environ. Radioact., 124, 147-159, 2013.

Sidle, R. C.: A conceptual-model of changes in root cohesion in response to vegetation management, J. Environ. Qual., 20, 4352,1991

Sidle, R. C., Ziegler, A. D., Negishi, J. N., Nik, A. R., Siew, R., and Turkelboom, F.: Erosion processes in steep terrain - Truths, myths, and uncertainties related to forest management in Southeast Asia, For. Ecol. Manage., 224, 199-225, 2006.

Strobl, C., Boulesteix, A. L., Kneib, T., Augustin, T., and Zeileis, A.: Conditional variable importance for random forests, BMC Bioinf., 9,doi:10.1186/1471-2105-9-307, 2008.

Walsh, R. P. D, Bidin, K., Blake, W. H., Chappell, N. A., Clarke, M. A., Douglas, I., Ghazali, R., Sayer, A. M., Suhaimi, J., Tych, W., and Annammala, K. V.: Long-term responses of rainforest erosional system at different spatial scales to selective logging and climatic change, Philos. Trans. R. Soc., B., 366, 3340-3353, 2011.

Watson, A., Phillips, C., and Marden, M.: Root strength, growth, and rates of decay: Root reinforcement changes of two tree species and their contribution to slope stability, Plant Soil, 217, 39-47, 1999.

Webb, A., Dragovich, D., and Jamshidi, R.: Temporary increases in suspended sediment yields following selective eucalypt forest harvesting, For. Ecol. Manage., 283, 96-105, 2012.

Zimmermann, A., Francke, T., and Elsenbeer, H.: Forests and erosion: Insights from a study of suspended-sediment dynamics in an overland flow-prone rainforest catchment, J. Hydrol, 428, 170-181, 2012. 